\title{
Wound Infection, CTCAE
}

National Cancer Institute

\section{Source}

National Cancer Institute. Wound Infection, CT CAE. NCI Thesaurus. Code C143951.

A disorder characterized by an infectious process involving the wound. 